\title{
Practice Case Study: Family Treatment \& Strategies An Academic Tool
}

\author{
Dr. Phillip D. Clingan
}

\begin{abstract}
The paper concentrates on the issue of a small family needing therapeutic intervention to bring about effective change. An explanation of this issue will provide families impacted by family conflicts and environmental influences that lead to stress and uncontrollable behaviors within the family structure. To solve this problem, Milton Erickson developed an important approach to therapy. By the 1950s, Jay Haley approached this problem by promoting a remedial strategy where the therapist takes a more hands-on approach. This approach means that the therapist creates and achieving change within the family. Strategic family therapy addresses family problems differently by dealing with only the immediate issues and not in terms of thoughts and feelings during treatment. Vital family therapy encourages clients through behavior adjustment and communication methods to reduce conflict barriers within the family structure.
\end{abstract}

Index Terms - Strategic family therapy, genograms, Therapeutic Tools, Detriangulation Process, Five Critical Questions, Behavior Modification, Parenting Strategies, Communication Strategy, Valancing Family Framework.

\section{INTRODUCTION}

Highlight Strategic family therapy is a beneficial process that focuses on issues in the briefest time frame possible. This remedial approach provides the therapist to establish and start what happens during the treatment session and develops a unique plan to approach the problem [6]. The homework assignment family control that takes place in the home. It is fundamental to the success of the treatment that families do their homework to create an effective change within the family dynamics that present the problems, which become identified in the session [6]. The goal is for the treatment to have a fruitful outcome.

Strategic family therapy is a hands-on approach by the therapist who attempts to insert him or herself into the family triangle. Primarily to identify the problem and discover a solution to the family problem [6]. Just as crucial is the communication plan to diagnose broken channels within the family system to restore the family structure and bring about effective change [6].

Even though not staying to the remedial plan will cause considerable disruption of performance, strategic family therapy remains a collaborative approach of the $21 \mathrm{st}$ century. On account of the strategy approach, particularly problem focus behavior modification is essential

Dr. Phillip D. Clingan, Criminal Justice \& Social Sciences, Pierce College/ Lakewood WA., United States
[6]. Strategic family therapy implements specific parenting strategies relating to the case study.

\section{A. Purpose Statement}

The paper intends to identify the process and therapeutic rationale for assessing family history, creating significant questions, and changing procedures. All areas used in a therapy session focused on assessment tools relating to a case study. The following summarizes the sources used as supportive evidence that important family therapy helps encourage change and reinforce solutions. To describe the significance of previously established sources and methods to explain results to the case study.

\section{METHOD}

\section{A. Scenario Sample}

Jason is a 40-year-old single father with one 14-year-old child, Roger. Mother abandoned the family when Roger was six. Mother is a drug user, has serious economic problems, and may have a bipolar disorder as her mother became diagnosed with bipolar disorder. Roger is scoring low academically, withdrawing emotionally, and asking questions about his mother. Father has informed his son that his mother is "no good," and that Roger had done better in school or be grounded.

Roger seldom leaves his bedroom and devotes several hours enjoying video games, several that involve violent content. Further, his hygiene has declined. Jason is an engineer and believes himself to be the stable force in his son's life. Jason prides himself in attempting to show his son the importance of values and work ethics. Jason has dated Sherry, a 32-year-old co-worker with whom he is spending an increasing amount of time.

\section{B. Method Applied to Assess Family}

The genograms are excellent tools formed of schematic diagrams that list and show how family members relate to one another [2]. Within the design are dates, ages, marriages, deaths, children, relatives, illnesses, and geological data. Most significant is how genograms are more than just a passive representation of a family, but a portrait of relationship conflicts, triangles, and cut-offs [6]. Seeing Rogers's grandmother diagnosed with bipolar disorder means nothing without understanding patterns of behavior passed down through generations [6].

\section{Therapeutic Tools}

Build an alliance during the initial interview and establish an engaging hypothesis concerning what the problem is, so the 
therapist does not jump to conclusions [6]. Establish a report to help the clients trust the therapist, and the therapist will gather information. Use the hypothesis to keep unnecessary stories from blending into the issue. Orient the clients to their backgrounds and speak to each individual personally and do not tolerate interruptions by others. When implementing the genogram, these therapeutic tools will help manage the session and subsequent sessions' serve and improve responsiveness [6].

\section{Positiveand Negative Results}

Although many therapists use genograms as a meditation tool, there are positive and negative effects. Discussing important events, such as marriages, deaths, and divorces, may produce an emotional shock wave throughout the family and merits careful consideration [6]. Absent information concerning cancer and bipolar disorder forgotten or not mentioned produces a break in the communication of important information [7]. The assessment illustrates significant segments of the family. Also, applying the genogram places the problem in a social and historical context [4].

\section{E. Additional Information and Informed Strategy}

Gathering further information regarding Jason (father) and Roger (son) will support the therapist strategize treatment opportunities. These opportunities will benefit the client understand further about their relationships and themselves so Roger and Jason can accept responsibility for their own lives [6]. The therapist asks questions using an extensive family management approach to help Roger and Jason stop blaming one another and discover the problem. By requesting further information about family patterns and issues, the therapist can create a treatment structure and facilitate the therapeutic process [6]. The strategy is to form a unique relationship by remaining in contact with Roger and Jason. While the therapist remains neutral, this will start the detriangulation process, which transforms the family system [6].

\section{RESULTS}

\section{A. Five Critical Questions}

Despite concentrating on the elements of the dilemma during the treatment session, identifying the strengths is most essential to a successful session (Nichols, 2010). Therefore, the therapist should offer flexibility by asking five critical questions in response to the above scenario: (a) what fathers and son do well together, (b) how have Roger and Jason handled problems in the past, (c) what does a hopeful future look like, (d) what behaviors and attitudes led to your relationship deteriorating, and (e) what has worked to bring father and son together [2].

\section{B. Purpose}

The family therapist examines the treatment process of family communication by asking questions, questions about how father and son refer to one another [6]. Inviting them to discuss the issues and dilemmas during the therapy session does this. Once the surface problem that led Roger and Jason to therapy becomes explained, and questions asked the therapist will set the family into context. This context helps organize the hypothesis and what needs to resolve the problem facing Roger and Jason [6].

\section{Strategy for Behavior Modification}

Using strategic family theory and treatment will facilitate the principal methods of the $21 \mathrm{st}$ century that encourage a therapist to be collaborative rather than manipulative, as in the case for Roger and Jason. Before teaching Roger specific parenting strategies, the therapist may introduce the mental research institute (MRI), model. This model will help Roger focus on what role the symptoms serve for him and Jason; only problem focal points behavioral change is essential [6].

\section{Specific Parenting strategies}

Teaching Jason to change Roger's behavior include operant conditions. Where Jason will use positive reinforcement rather than aversive control such as grounding him for eternity. Operant techniques include building, token economies, contingency contracting, contingency management, and time out [6]. Shaping helps Roger reinforce small changes while token economies teach Roger how to use a point system to reward Jason for appropriate behavior. Being innovative is necessary as Jason is 14; so small adjustments to this plan become needed. It will be contingency-contracting agreements made between Roger and Jason and follow the changes made by Jason and Roger [6].

\section{E. Therapeutic Basis}

The foundation of the assessment determines which behaviors to decrease and increase. Using a behavioral-based theory, such as parent and child interaction therapy (PCIT), will enhance the family system [6]. Also, they can use PCIT to assist Roger and the therapist in determining why Jason is experiencing difficulty at school. Behavioral interventions, such as PCIT help with Jason's oppositions and manage disorders such as attention deficit hyperactivity disorder (ADHD) [3]. PCIT will help distinguish other challenging conditions to reduce resistance between father and son.

\section{F. Positive and Negative Results}

Applying these therapeutic tools will have a positive impact that teaches Jason to practice his parenting skills. To eliminate criticism and sarcasm, but to praise good behavior and learn to ignore minor misbehaviors. These strategies will help change Rogers's behavior. A negative identifier will present itself if Roger implements variations to his approach. Not staying to the therapeutic plan will disrupt routines in both Roger and Jason, thus creating new weaknesses and consequences of problematic behavior [6].

\section{G. Communication Strategy}

The objective is to develop specific communication patterns between Roger and Jason which are creating and sustaining the problems [6]. To achieve this, they must make the determination to identify if Roger spends time with Jason. This factor becomes influenced by Rogers' work and limited by the work-family balance [5]. Roger needs to be involved in Jason's everyday routines and establish and cultivate a closer father-son relationship. 


\section{H. Therapeutic Reasoning}

By Roger spending, the "reasonable" amount of time with Jason, the child may stop living unsociably, and increase out of bedroom activities, less violent gaming, and school performance boosted. These are all indicators of independent growth of Jason and Rogers's work and family balance [5]. Jason assisting Roger with homework helps, yet not because the act helps increase academic performance, but inspires shared quality life and a pattern of healthy parenting [5].

\section{Positive and Negative Results}

When Roger experiences peer pressure, emotional and behavioral issues, Jason may feel he has failed as a parent. Since Roger is experiencing these obstacles, Jason is responsible as the father [5]. By implementing a positive communication strategy, Roger's work ethic may create a positive event that endows Jason with family values. Proper communications within the work-family are a positive symbol of balance and obligations fulfilled by all [5].

\section{DISCUSSION}

\section{A. Balancing Family Framework}

The importance of Roger and Jason repairing their relationship as father and son becomes indispensable; while improving quality family involvement strategies to strengthen the family dynamic [1]. The father and son must harmonize their individual and family obligations. The Bowen family therapy systems highlight the family's best framework. While counterbalancing two significant forces which drive the father and son relationship; togetherness and individualism [6]. Balance grows into success when father and son have learned to manage the relationship.

\section{CONCLUSION AND NEEDS FOR ADDITIONAL RESEARCH}

The results provide insights into determining the process and therapeutic rationale for evaluating family history, therapeutic tools, critical questions, behavior modification strategies, and a communication strategy. Testing different methods and procedures of strategic family therapy confirm the complex nature of the therapeutic profession. Overall, the case study achieved its purpose, showing various treatment approaches and methods used. Family planning to influence father and son behavior and communications associated with the family system. More research remains needed to understand the strategic family therapy process and therapeutic approach and therapist procedures for assessing family history.

\section{ACKNOWLEDGMENT}

I am using this opportunity to express my gratitude to my family and friends who supported me throughout the course of this research project. I am thankful for their aspiring guidance, invaluably constructive criticism and friendly advice during the project work. I am sincerely grateful to them for sharing their truthful and illuminating views on a number of issues related to the project.

\section{REFERENCES}

[1] Bonn, K., \& Neal, M. (2004). Balancing Work AndFamily: What Makes It Easy Or Hard? The Gerontologist, 44(1), 388. Retrieved from http://search.proquest.com/docview/210988855?accountid=39364

[2] [2\}Duba, J. D., Graham, M. A., Britzman, M., \&Minatrea, N. (2009). Introducing the "Basic Needs Genogram" in Reality Therapy-based Marriage and Family Counseling. International Journal of Reality Therapy, 28(2), 15-19. Retrieved from http://www.rockies.edu/proquest/

[3] [3] Jimenez, M. E., \& Guevara, J. P. (2013, October 15). A 7-year-old boy experiencing difficulty at school. Canadian Medical Association Journal, 185(15), 1333-

[4] Retrieved from http://search.proquest.com/ docview/1450319923? accountid=39364

[5] McGoldrick, M., Carter, B., \& Garcia-Preto, N. (2011). The Expanded family Life Cycle: Individual, Family, And Social Perspectives (4th ed.). Boston, MA: Allyn \& Bacon.

[6] Milkie, M. A., Kendig, S. M., Nomaguchi, K. M., \& Denny, K. E. (2010). Time With Children, Children's Well-Being, and Work-Family Balance Among Employed Parents. Journal of Marriage and Family, 72(5), 1329-1343. Retrieved from http://search.proquest.com/docview/759963813? accountid=39364

[7] Nichols, M. P. (2010). Family Therapy, Concepts And Methods (9 ed.). Boston: Allyn \& Bacon.

[8] Smith, J. A., Dancyger, C., Wallace, M., Jacobs, C., \& Michie, S. (2010, September 11). The Development of a Methodology for Examining the Process of Family Communication of Genetic Test Results. National Society of Genetic Councelors, 20, 23-34. http://dx.doi.org/10.1007/s10897-010-9317-x

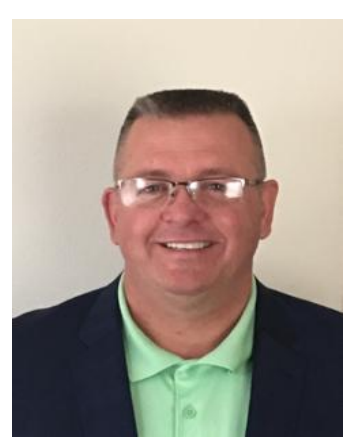

Dr. Clingan after serving 21 years in the United States Army undertook his Psy.D in the Department of Psychology, specializing in criminology in the School of Organizational Leadership at Ashford University, Denver, Colorado. $\mathrm{He}$ is a faculty member teaching in the Departments of Psychology and Criminal Justice in San Antonio, Texas for Pierce College and serves as a content expert on dissertation committees for Grand Canyon University School of Doctoral Studies regarding quantitative studies for doctoral candidates. Dr. Clingan specializes in preeminent psychology as applied within the field of criminology. His psychology work is based upon field experience in criminal trials since 2013 and heavily influenced by the theoretical frameworks of Dr. Paul Ekman and measuring nonverbal communication. Loves writing and riding his Indian Motorcycle. 